\title{
Photocatalytic Degradation of Methylene Blue and Methyl Orange by Y-PTC Metal-Organic Framework
}

\author{
Adawiah Adawiah ${ }^{1}$, Muhammad Derry Luthfi Yudhi ${ }^{2}$, Agustino Zulys ${ }^{2 *}$ \\ ${ }^{1}$ Integrated Laboratory Centre, Faculty of Science and Technology, UIN Syarif Hidayatullah Jakarta \\ Jl. Ir. H. Juanda No. 95 Ciputat South Tangerang 15412, Indonesia \\ ${ }^{2}$ Department of Chemistry, Faculty of Mathematics and Natural Sciences, University of Indonesia \\ Jl. Lingkar Kampus Raya, Pondok Cina, Beji, Depok, Jawa Barat 16424, Indonesia
}

*Corresponding author: zulys@ui.ac.id

Received: August 2021; Revision: October 2021; Accepted: November 2021; Available online: November 2021

\begin{abstract}
The yttrium based metal-organic framework (MOF) Y-PTC was synthesized by the solvothermal method using perylene as the linker and yttrium as metal ion. This study aims to assess the photocatalytic activity of yttriumperylenetetracarboxylate (Y-PTC) metal-organic framework (MOF) toward methylene blue and methyl orange under visible light irradiation. The results of the FTIR analysis showed that Y-PTC MOF had a different structure and composition from its precursor $\left(\mathrm{Na}_{4} \mathrm{PTC}\right)$. The Y-PTC MOF has a bandgap energy value of 2.20 $\mathrm{eV}$ with a surface area of $47.7487 \mathrm{~m}^{2} / \mathrm{g}$. The SEM-EDS analysis showed an elemental composition of yttrium, carbon, and oxygen, were $6.9 \%, 72.1 \%$ and $20.7 \%$, respectively. Furthermore, Y-PTC MOF was able to adsorb dyes at the optimum by $78.10 \%$ and $35.57 \%$ toward methylene blue (MB) and methyl orange (MO) at the dispersion period of 60 mins. Y-PTC MOF exhibited photocatalytic activity towards the degradation of methylene blue and methyl orange under visible light irradiation. The addition of $\mathrm{H}_{2} \mathrm{O}_{2}$ inhibited Y-PTC photocatalytic activity towards $\mathrm{MO}$ degradation from $50.89 \%$ to $26.38 \%$. In contrast to $\mathrm{MO}$, the addition of $\mathrm{H}_{2} \mathrm{O}_{2}$ had a positive effect on MB, which increased the degradation from $87.56 \%$ to $91.65 \%$. Therefore, Y-PTC MOF possessed the potential of a photocatalyst material in dyes degradation under visible light irradiation.
\end{abstract}

Keywords :Metal-organic framework, yttrium-perylene, methylene blue, methyl orange.

DOI: $10.15408 / j k v . v 7 i 2.22267$

\section{INTRODUCTION}

Photocatalytic technology based on semiconductor materials has been receiving great attention in the development of wastewater treatment for annihilating dye contaminants, due to being cheap and environmentally friendly. Several semiconductor materials were used in this process, namely oxides of titanium, zinc, and other metals (Ramasundaran et al., 2016). However, these materials have limitations, such as high photocatalytic activity which required ultraviolet light, low adsorption capacity and difficult separation processes. Therefore, the development of a new semiconductor material is very important to increase photocatalysis effectiveness and to degrade dye contaminants on wastewater under visible light irradiation.
The use of metal-organic frameworks (MOFs) as materials in photochemical reactions has been broadly developed for wastewater which that dye contaminants (Wang et al., 2014). MOFs are crystalline materials formed by ions and coordinated with the linkers. They exhibited interesting properties in degrading dye contaminants in wastewater such as large surface area, abundant active sites, high stability in water, and adjustable structures.

Previous studies succeeded in synthesizing a metal-organic framework based on perylene ligands which showed responsiveness to visible light. Sikdar et al., (2016) reported that perylene-based MOFs, namely $\left(\mathrm{K}_{8}(\mathrm{PTC})_{2}\left(\mathrm{H}_{2} \mathrm{O}\right)_{1.5}\right) .4 \mathrm{H}_{2} \mathrm{O}$, have semiconductor characters with a bandgap energy of $2.53 \mathrm{eV}$. Zulys et al., (2020) 
mentioned that nickel linked with perylene ligand, namely Ni-MOF, have bandgap energy of $2.41 \mathrm{eV}$, and the maximum absorption in the $514 \mathrm{~nm}$. Christina et al., (2020) have succeeded in synthesizing perylene-based DyMOF and Sm-MOF, with bandgap energies of $2.182 \mathrm{eV}$ and $2.196 \mathrm{eV}$, respectively for water splitting reactions under visible light irradiation. This showed that the use of perylene as an organic ligand in the MOFs fabrication increases MOFs responsiveness to the visible light spectra.

Perylene 3,4,9,10-tetracarboxylate is an organic ligand, with a functional group in the form of a carboxylate $\left(\mathrm{COO}^{-}\right)$. Based on Pearson's hard/soft acid/base (HSAB) principle, the ligands with carboxyl functional groups are included in the hard base group, which interact with metal ions containing a high valence of 3 and 4 (hard Lewis acids) to form a stable MOFs, both in water and acidic conditions (Yuan et al., 2018). In order to obtain MOF with good stability, a metalorganic framework based on perylene ligand is synthesized using yttrium with the valence of 3 . Furthermore, the uses of yttrium as the metal source and perylene as the ligand for MOFs fabrication for dye degradation under visible light irradiation has never been carried out before. Hence, this research was carried out to synthesize, characterize and evaluate the yttrium-perylenetetracarboxylate (Y-PTC) MOFs as the photocatalyst to degrade methylene blue (MB) and methyl orange (MO) as cationic and anionic dye.

\section{MATERIALS AND METHODS Materials}

Glassware, hotplate, magnetic stirrer, rotary evaporator, analytical balance, a set of reflux equipment and spatulas were used in the research. The instrumentation equipment used were Fourier Transform Infrared (FTIR) Prestige 21 Shimadzu, X-Ray Powder Diffraction (XRD) Shimadzu 6000 and Diffuse Reflectance Spectrophotometer UV (Shimadzu spectrophotometer 2200A).

The materials used were yttrium nitrate hexahydrate $\left(\mathrm{Y}\left(\mathrm{NO}_{3}\right)_{3} \cdot 6 \mathrm{H}_{2} \mathrm{O}\right)$ (Sigma-Aldrich), $\mathrm{NaOH} \quad$ (Merck), Perylene-3,4,9,10tetracarboxylic dianhydride (Sigma-Aldrich), $\mathrm{N}, \mathrm{N}$-dimethylformamide (DMF), ethanol (Merck), methanol (Merck), and distilled water.

\section{Preparation of $\mathrm{Na}_{4}$ PTC from perylene- $3,4,9,10$ tetracarboxylic dianhydride (PTCDA) \\ PTCDA $(0.5 \mathrm{~g}, \quad 1.27 \mathrm{mmol})$ was} dissolved in distilled water $(50 \mathrm{~mL})$ and added with $\mathrm{NaOH}(0.356 \mathrm{~g}, 8.9 \mathrm{mmol})$ further stirring vigorously. The resulting greenish solution was filter and the filtrate was added with excess ethanol to obtain a yellow precipitate. The $\mathrm{Na}_{4} \mathrm{PTC}$ precipitate was then filtered, washed with ethanol, and dried at room temperature.

\section{Synthesis of Y-PTC MOF}

$\mathrm{Y}\left(\mathrm{NO}_{3}\right)_{3} \quad(2 \mathrm{mmol})$ and $\mathrm{Na}_{4} \mathrm{PTC}$ (1 mmol) were dissolved in the mixture of $N, N$ dimethylformamide $(5 \mathrm{~mL})$ and distilled water $(25 \mathrm{~mL})$. The mixture was then stirred for 45 mins at a speed of $300 \mathrm{rpm}$, then transferred to Teflon and autoclaved for 24 hours at $170{ }^{\circ} \mathrm{C}$. The resulting precipitate was filtered, and the crystals formed were washed with distilled water and DMF, then dried at $70^{\circ} \mathrm{C}$ overnight.

\section{Characterization of MOF Y-PTC}

The synthesized Y-PTC was then analyzed by X-Ray Diffractometer (XRD). The XRD diffraction was recorded on a Shimadzu 6000 diffractometer (Shimadzu Corporation, Kyoto, Japan), using $\mathrm{Cu}-\mathrm{K} \alpha$ irradiation $\left(\lambda=1.5406 \mathrm{~A}^{\circ}\right)$. The Shimadzu Prestige 21 spectrometer was used to record the Y-PTC MOF IR spectra at room temperature in the spectral range of 400-4000 $\mathrm{cm}^{-1}$ and a resolution of $4 \mathrm{~cm}^{-1}$. The samples were prepared in pellet form with $\mathrm{KBr}$. The spectra analysis was performed to determine the functional groups formed in the bond between the metal and ligands on the MOF. The diffuse reflectance spectroscopy (DRS) measurements were carried out using a Shimadzu 2200A spectrophotometer $(\lambda=250$ $800 \mathrm{~nm}$ ), with $\mathrm{BaSO}_{4}$ powder as a blank. The band gap energy of the MOF was determined using the Kubelka Munk equation;

$\mathrm{F}(\mathrm{R})=\frac{(1-R)^{2}}{2 R}$

Where, $\mathrm{R}=$ reflectance, $\mathrm{F}(\mathrm{R})=$ coefficient of extension $(\alpha)$. Modification of the KubelkaMunk function with the photon energy (hv) and the coefficient associated with the electronic transition (n) gives the equation:

$\alpha(h v) \approx B(h v-E g)^{n}$ 
Where:

$\alpha=\mathrm{F}(\mathrm{R})=$ The extinction coefficient

$\mathrm{B}=$ Absorption constant

$\mathrm{Eg}=$ bandgap energy $(\mathrm{eV})$

$\mathrm{h}=$ Planck's constant $(6,626 \times 10-34 \mathrm{~J} . \mathrm{s})$

$\mathrm{v}=$ radiation frequency $\left(\mathrm{v}=\mathrm{c} / \lambda \mathrm{s}^{-1}\right)$

$\mathrm{n}=$ allowable electronic transition values $(\mathrm{n}=$

2 for indirect transitions, plotted as $(\alpha \mathrm{hv})^{1 / 2}$ versus $E, n=1 / 2$ for a direct transition, plotted as $(\alpha h v)^{2}$ versus E).

The morphology and elemental composition Y-PTC were analyzed using the FEI Quanta 3D FEG scanning electron microscope, operating at a voltage of $25 \mathrm{kV}$. The MOF was closed with Au to amplify the secondary electron signal. The ASAP Micromeritic BET analyzer 2020 was used to analyzing the specific surface area of the MOF. The thermal stability and the adsorbed water content were analyzed using the thermal gravity analysis (TGA) instruments.

\section{RESULTS AND DISCUSSION}

The Conversion of Perylene-3,4,9,10Tetracarboxylate Dianhydrate (PTCDA) into Sodium perylene tetracarboxylate ( $\mathrm{Na}_{4}$ PTC)

Perylene-3,4,9,10-tetracarboxylic dianhydride (PTCDA) used as an organic linker in the MOF Y-PTC material synthesis, and was converted to a salt form further called $\mathrm{Na}_{4}$ PTC (sodium perylene-3,4,9,10tetracarboxylate) before used through the hydrolysis reaction using sodium hydroxide $(\mathrm{NaOH})$ as the catalyst in the hydrolysis reaction. This conversion process was carried out to increase the perylene ligand solubility in water at neutral $\mathrm{pH}$, considering that the synthesis of Y-PTC MOF was carried out using the solvothermal method where a mixture of water and DMF (5:1) used as a solvent.

The addition of the $\mathrm{NaOH}$ as the base catalyst changed PTCDA compound into $\mathrm{Na}_{4}$ PTCA, the salt form of PTCDA as indicated by the color change of the solution from red to reddish-green (Figure 1). The hydroxide ion from $\mathrm{NaOH}$ acted as a nucleophile that reacts with PTCDA, caused the cyclic anhydride bond to open and forming perylene-3,4,9,10-tetracarboxylate

(PTC) anion through the substitution nucleophilic two (SN2) mechanism. The ionic bond between sodium ions and carboxylate anions then formed from PTC to form $\mathrm{Na}_{4}$ PTC salts that dissolved in water with the reaction equation as shown in Figure 2. $\mathrm{Na}_{4} \mathrm{PTC}$ showed luminescence characteristics as indicated by a green-yellowish color, which gave a fluorescent effect that can be found in molecules with many conjugated $\pi$ bonds, such as the perylene tetracarboxylate (PTC) anion.

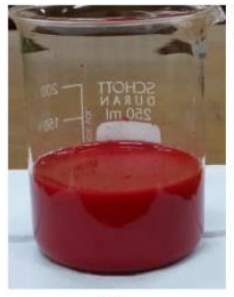

(a)

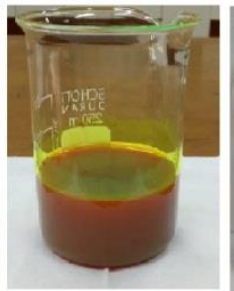

(b)

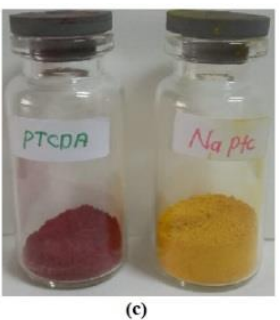

Figure 1. (a) PTCDA suspension in water, (b) $\mathrm{Na}_{4}$ PTC solution, (c) PTCDA powder and $\mathrm{Na}_{4} \mathrm{PTC}$

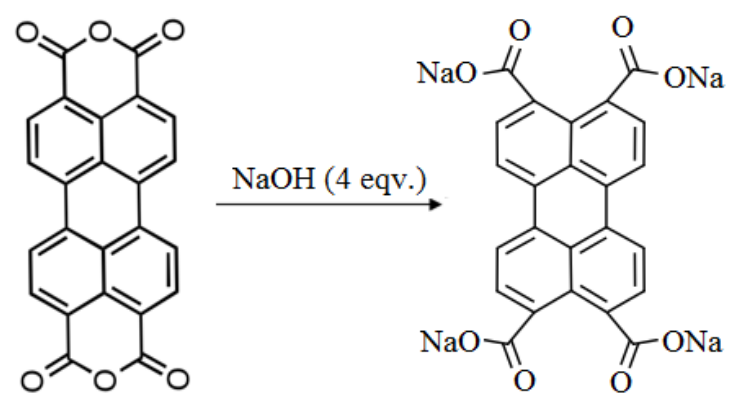

Figure 2. The hydrolysis reaction of PTCDA becomes $\mathrm{Na}_{4}$ PTC

The resulting $\mathrm{Na}_{4} \mathrm{PTC}$ salt precipitate was filtered and washed with ethanol until a neutral $\mathrm{pH}$ was obtained to remove residual hydroxide ions after the hydrolysis reaction. The resulting $\mathrm{Na}_{4}$ PTC salt precipitate further analyzed using FTIR to confirm the presence of carboxylate ion groups in the salt. The resulting $\mathrm{Na}_{4}$ PTC salt has a yield percentage ranging from $65-75 \%$, with physical characteristics in the form of a yellow powder, and higher solubility in water than PTCDA.

Figure 3 shows the IR spectra of the perylene-3,4,9,10-tetracarboxylic dianhydride (PTCDA) and $\mathrm{Na}_{4}$ PTC. The IR spectrum of perylene 3,4,9,10-tetracarboxylate showed the absorption peak spectrum specifically produced by PTCDA. This included the sharp absorption peak at wavenumber of $1767 \mathrm{~cm}^{-1}$, which indicated an anhydrous compound group of a 5-member cyclic ring PTCDA. Then the wavenumber of $1753 \mathrm{~cm}^{-1}$ and 1730 
$\mathrm{cm}^{-1}$, which were identified as the asymmetric and symmetric stretching vibrations $(\mathrm{C}=\mathrm{O})$ on the anhydrous compound of a 5-member cyclic ring PTCDA. A sharp spectrum peak also appeared at the wavenumber of $1234 \mathrm{~cm}^{-1}$ and $939 \mathrm{~cm}^{-}{ }^{1}$, which were identified as asymmetric and symmetric stretching vibration $(\mathrm{C}-\mathrm{O})$ from the C-CO-O-CO-C- group, on the cyclic anhydride compound of PTCDA.

The IR spectrum characteristics in Figure 3 also showed that the five peaks of the specific wavenumber possessed by the PTCDA compound did not appear in the $\mathrm{Na}_{4}$ PTC IR spectrum. Furthermore, the $\mathrm{Na}_{4} \mathrm{PTC}$ IR spectrum also indicated a new absorption that appeared at a wavenumber of $1633 \mathrm{~cm}^{-1}$ and
$1423 \mathrm{~cm}^{-1}$, which were identified as the asymmetric and symmetric stretching vibrations of the carboxylate (-COO) ion compound. The emergence of new absorption at these wavenumbers indicated that PTCDA formed a carboxylate anion with sodium cation from $\mathrm{NaOH}$ solution. In the IR spectrum of both PTCDA and $\mathrm{Na}_{4}$ PTC, there was no absorption spectrum for $-\mathrm{OH}$ in the wave number range of 2500-3300 $\mathrm{cm}^{-1}$. This showed that PTCDA reacted with four equivalents of sodium hydroxide to form sodium perylene tetracarboxylate $\left(\mathrm{Na}_{4} \mathrm{PTC}\right)$ salt, with a chemical reaction equation as shown in Figure 2.
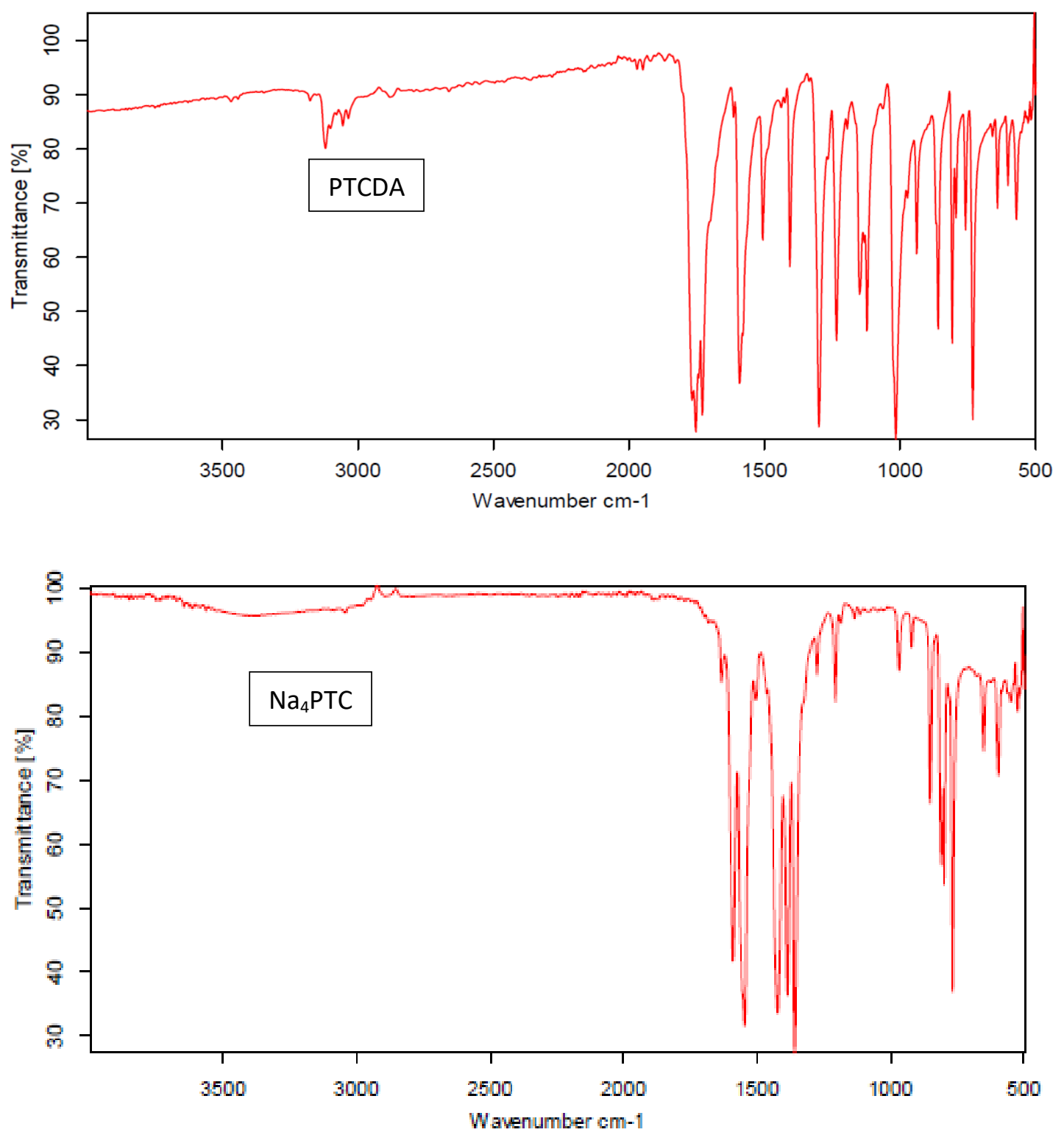

Figure 3. IR reference spectrum of PTCDA and $\mathrm{Na}_{4} \mathrm{PTC}$. 


\section{Metal-Organic Framework Y-PTC}

The metal-organic framework (MOF) developed in this study uses yttrium (Y) as the metal ion and perylene $(3,4,9,10$ tetracarboxylic dianhydride) as as organic linker. The use of PTCDA as a ligand precursor was intended to obtain a MOF-based photocatalyst material that is responsive to visible light, due to the high $\pi$-conjugated bonds in the PTCDA. It was capable not only as a ligand in the formation of the framework but also as a photosensitizer in increasing the sensitivity of MOF to visible light. Meanwhile, the use of yttrium as a metal center was intended to obtain photocatalyst material with a narrow band gap energy for expanding the absorption area to the visible light region. The resulting MOF was also expected to have good thermal, light, and chemical stability, particularly in water, acids, and alkalis to obtain stable material. The stability of a monomeric MOF, such as MOF Y-PTC was largely determined by the strength of the bonds between the yttrium with the ligands. The strong bond between the metal-ligands increased the stability and protect the MOF from the hydrolysis process. Metals with a high charge $\left(\mathrm{M}^{3+}\right.$ or $\left.\mathrm{M}^{4+}\right)$ acted as hard Lewis acids and interacted to form bonds with ligands that have a carboxyl functional group $\left(\mathrm{COO}^{-}\right)$ which is a hard Lewis base. Therefore, it is expected that the use of PTCDA as a ligand with a carboxyl group and yttrium metal $\left(\mathrm{Y}^{3+}\right)$ generated MOF-based photocatalysts that are responsive to visible light with relatively narrow bandgap energy and good stability (Yuan et al., 2018).

In this study, the MOF Y-PTC synthesis was carried out through the solvothermal method by using a mixture of water and $N, N$ dimethylformamide (DMF) with a ratio of 5:1 and a total volume of $30 \mathrm{~mL}$. Before undergone the reaction, both the salts of each metal and the $\mathrm{Na}_{4}$ PTC ligands were dissolved in a separate vessel to facilitate the dissolution and ionization process and the resulting solution will be more homogeneous. Thus, the coordination reaction or formation of MOF compounds between metal ions and carboxylate anions occurs rapidly. After being mixed, stirring was applied to induce the homogeneity and did not leave a precipitate at the bottom of the glass. The mixture was then placed in a Teflon-lined stainless-steel bomb reactor, which was tightly closed and placed into an oven at $170{ }^{\circ} \mathrm{C}$ for 24 hours.

The solvothermal method was used since it was easy to conduct, overcome obstacles that occur in the MOF crystal growth process as well as preventing the formation of reversible reactions that cause crystals dissolution. The mixed water solvent system and the DMF used in the Y-PTC MOF synthesis were aimed to avoid defects in the MOF crystal framework. This was because the mixed solvent system was able to adjust the solution polarity and provides a suitable template to be filled by molecules, which was important in constructing a defect-free crystalline framework.

The MOF produced generated a percent yield ranging from $45-60 \%$ in the form of a fine powder with a brown color (Figure 4). The Y-PTC MOF was insoluble in water, DMF, methanol, and acid solutions.

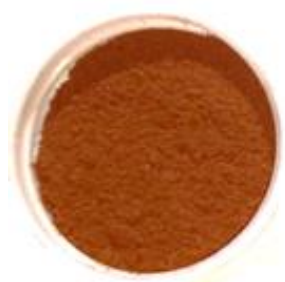

Figure 4. MOF Y-PTC

\section{X-Ray Diffraction and Crystallinity}

The X-Ray Diffraction characterization on the MOF Y-PTC material was carried out to determine the pattern formed and the crystallinity degree of the Y-PTC. This was considered necessary to confirm the structure, composition and particularly the crystallinity degree of the MOF. This is related to its application as a photocatalyst material since the crystallinity degree will affect the reaction and its photocatalytic activity.

Kudo and Miseki, (2009) reported that the crystal structure and particle size affect photocatalytic reactions, especially in the separation and migration stages of the charge from photogenerated carriers which are strongly influenced by the crystal structure of the material including crystallinity, defects, and distortion. The higher crystal quality of material, the smaller of defects number. Crystal defects acted as trapping and recombination centers between excited electrons and holes, which reduce photocatalytic activity. With the high crystallinity degree of a photocatalyst material, 
the recombination process is inhibited. Furthermore, when the crystal size of the material becomes very small, the distance of the excited electrons and holes migrating to the reaction side on the photocatalyst surface becomes shorter. This occurred to reduce the possibility of a recombinant process between excited electrons and holes.

Metal-organic framework (MOF) has been recognized as a material with high crystallinity, however, MOF material can have crystal defects. Generally, the crystallinity of a material increases with increasing reaction temperature. Therefore, it is very important to analyze the crystal structure including the diffraction pattern and the crystallinity degree at the MOF. The results of the X-Ray Diffraction of Y-PTC characterization are shown in Figure 5. This figure showed that the crystallinity degree of Y-PTC is very low. This was shown from the low peak intensity value of the spectrum from Y-PTC, as well as the high background value. The spectrum of the diffractogram patterns on both Y-PTC showed a sharp spectrum peak, with the highest intensity at a value of $2 \theta=17.04^{\circ}, 26.27^{\circ}$, and $27.41^{\circ}$ for Y-PTC.

\section{FTIR Spectroscopy and Functional Group Analysis \\ FTIR spectroscopy was used to} qualitatively analyze functional groups present in a compound. The characterization with FTIR was carried out to compare the absorption peaks that appeared in the spectrum of $\mathrm{Na}_{4} \mathrm{PTC}$ precursor ligands, Y-PTC and to determine the changes that occurred due to the formation of MOFs that had different structures from the precursor compounds (Figure 6). Therefore, FTIR characterization is used as an indicator to determine the success of each stage of the synthesis process carried out.

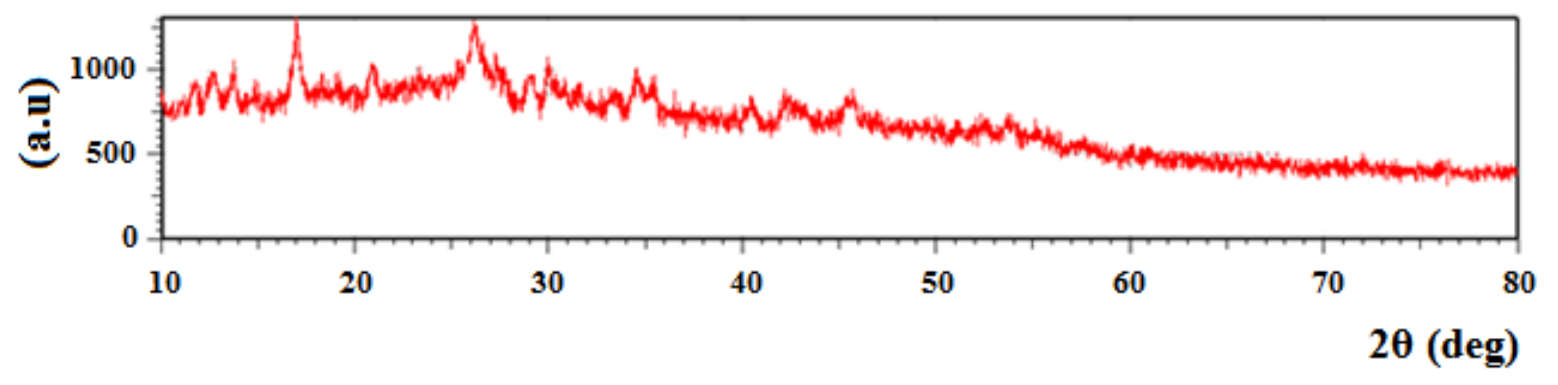

Figure 5. Y-PTC MOF diffraction pattern

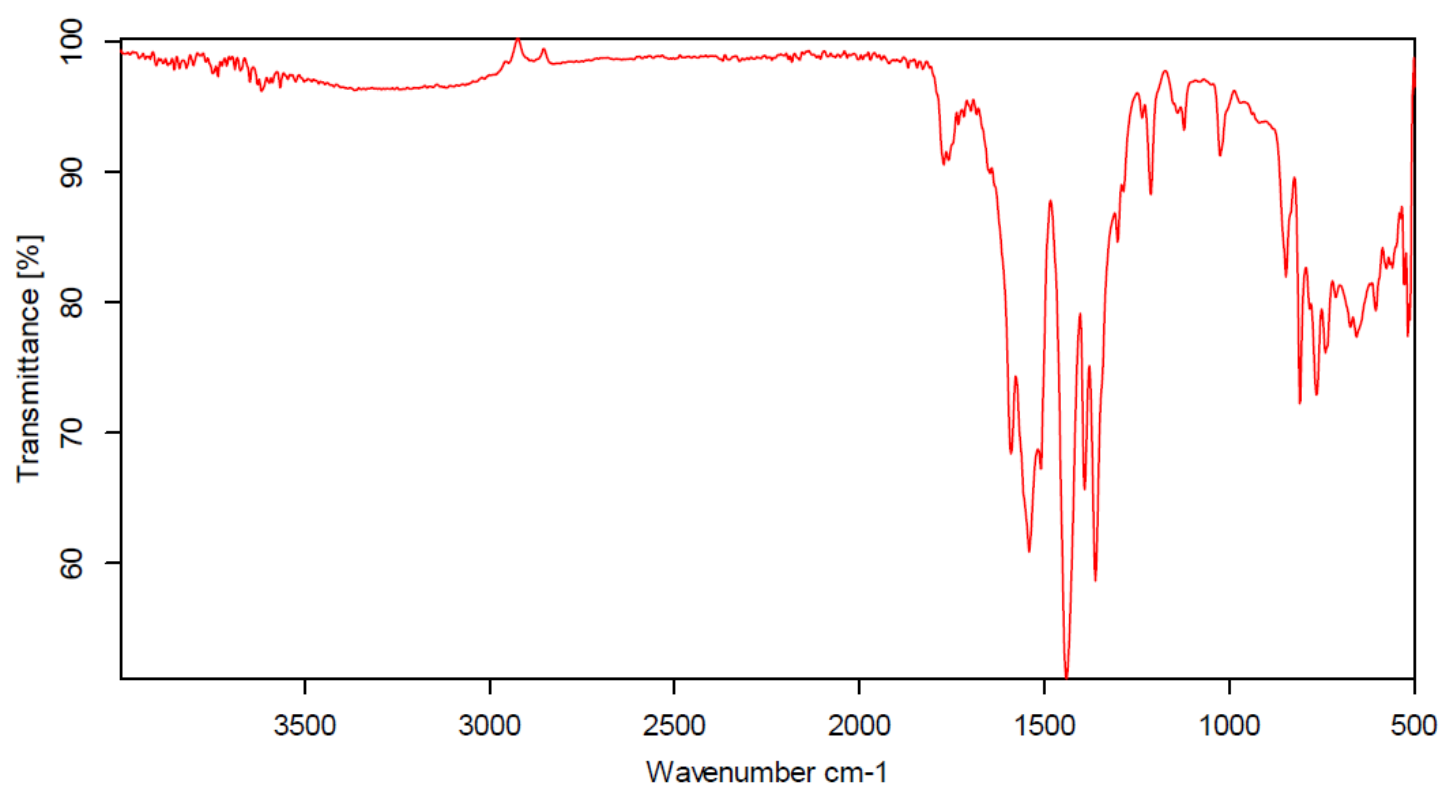

Figure 6. MOF Y-PTC IR spectrum 


\section{UV-Vis Diffuse Reflectance Spectrometry Analysis}

UV-Vis Diffuse Reflectance

Spectrometry (DRS) analysis was also used to determine the band gap energy value of a material. The determination of the bandgap energy (Eg) value is one of the factors that semiconductor materials should possess in the photocatalytic system. It is the energy distance between the valence and the conduction band, determines how much minimum energy the photocatalyst material requires for the photocatalytic process and identifies the wavelengths of the light source used, both in the UV and in the visible light area. In photocatalytic reactions with the help of photon energy from visible light, the bandgap energy $(\mathrm{Eg})$ value that a photocatalyst material should possess is $\mathrm{Eg} \leq 3.0 \mathrm{eV}$ range. This is the maximum value for a photocatalytic ability to manifest in the visible light areas.

The bandgap energy value $(\mathrm{Eg})$ is determined using the Kubelka-Munk equation combined with the Tauc plot. The reflectance spectrum generated from the UV-Vis DRS measurement process was translated into an absorption spectrum by the Kubelka-Munk method. The determination of the bandgap energy value using the Kubelka-Munk equation and the Tauc plot assumes the interaction of light passing through a thin layer of material where the thickness is neglected to the reflectance value. Therefore, the KubelkaMunk equation for each wavelength is written as:

$(R)=\frac{K}{S}=\frac{(1-R)}{2 R}$

Where $F(R)$ is a function of the KubelkaMunk, while $\mathrm{R}$ is the reflectance value. $\mathrm{K}$ and $\mathrm{S}$ are the absorption and the scattering coefficient, respectively. To determine the value of the bandgap energy, a Tauc plot approach is used with the following equation:

$\alpha \mathrm{h} v=(\mathrm{h} v-E g)$

Where $h$ is the Plank constant, $v$ is the vibrational frequency, $\mathrm{A}$ is the proportional constant, and $\alpha$ is the linear absorption coefficient which is substituted for the Kubelka-Munk equation when it is assumed that the incident light is completely scattered. Therefore, using equations 2 and 3, a linear equation is obtained, which is used to determine the bandgap energy value $(\mathrm{Eg})$ :

$\left[\mathrm{F}(R)^{*} \mathrm{~h} v\right]^{1 / n}=A(\mathrm{~h} v-E g)$

From this equation, the relationship plot between $\left[\mathrm{F}(\mathrm{R})^{*} \mathrm{~h} v\right]^{1 / \mathrm{n}}$ on the $\mathrm{y}$-axis, and $\mathrm{h} v$ on the $\mathrm{x}$-axis is determined. The bandgap energy value $(\mathrm{Eg})$ is obtained with the $\mathrm{h} v$ value when $\mathrm{y}$ or $\left[\mathrm{F}(\mathrm{R})^{*} \mathrm{~h} v\right]^{1 / \mathrm{n}}$ equals zero. The $\mathrm{n}$ value in equation 4 is influenced by the electronic properties of the material, where $n=1 / 2$ for those experiencing direct allowed transition and $\mathrm{n}=2$ for the indirect allowed transition. In determining the direct or indirect transition material, further analysis is needed on the momentum of the conduction and the valence band. The energy value of the bandgap (Eg) for Y-PTC is $2.20 \mathrm{eV}$ and $1.76 \mathrm{eV}$ for the direct and indirect allowed transmission systems, respectively. Both MOFs have a maximum absorption in the visible area, which is in the 551-742 $\mathrm{nm}$ range. However, by comparing the maximum absorption value in both systems, the spectrum curve of the relationship between the wavelengths and the percent reflectance of the two MOFs, it is stated that MOF Y-PTC has increased in percent in reflectance or a decreased in percent absorbance in the wavelength range above 600 $\mathrm{nm}$. Therefore, it is stated that the resulting YPTC exhibited a direct allowed transition material with a bandgap energy value of 2.20 $\mathrm{eV}$ or a maximum absorption in the $563 \mathrm{~nm}$ wavelength region. The results of the UV-Vis DRS analysis indicated that the resulting YPTC was responsive to visible light.

The low bandgap energy value in the YPTC is caused by the effect of the $\pi-\pi^{*}$ electronic transition on the conjugated $\pi$ bonds from the perylene ligands used. Perylene has more conjugated $\pi$ bonds than 2,6naphthalenedicarboxylic acid. It is a polyaromatic compound with five aromatic rings and a higher conjugation degree, while 2,6-naphthalenedicarboxylic acid has two aromatic rings. In a conjugated bonding system, an overlapping occurs in the $\pi$ orbitals, reducing the energy gap between neighboring orbitals. This causes a bathochromic shift in the absorption spectrum, and an increase in the intensity of light absorption. Therefore, the greater the conjugation degree, the higher the shift. Band gap energy of MOF La-PTC based PTCDA ligand is lower than band gap energy 
of La-MOF based 2,6-naphtalenedicarboxylic that are $2.25 \mathrm{eV}$ and $3.10 \mathrm{eV}$ for La-PTC and La-MOF respectivelly (Zulys et al., 2021; Batubara \& Zulys, 2019).

In the conjugated $\pi$ bonding system, an electron is normalized to a higher energy level when it absorbs a photon at the appropriate wavelength. Generally, the electrons move from the $\pi$ to the anti- $\pi\left(\pi-\pi^{*}\right)$ bonding orbital. The addition of the double bond makes the system absorb photons in a wider wavelength due to the increased resonance stability from the excited state. For example, the aromatic polynuclear compound such as naphthalene (2 rings) has a maximum absorption area of 280 $\mathrm{nm}$. Tetracene (4 rings) and pentacene (5 rings) have a maximum absorption area of 470 $\mathrm{nm}$ and $575 \mathrm{~nm}$, respectively.

The bandgap energy values of several perylene ligand-based MOF materials with several metals synthesized are shown in Table 1. The Eg values in the MOF materials based on rare earth metals (dysprosium, samarium and lanthanum) are not much different from those in PTCDA precursors. This shows that the use of metals from the lanthanide group does not cause a significant change in the bandgap energy value since rare earth metals were generally used in making heterogeneous photocatalysts to construct crystal structures although not used in making energy structures. Kudo and Misaki 2009 stated that the metals of alkaline, alkaline earth, and lanthanide do not directly contribute to the formation of energy bands. However, they contribute to the construction of crystal structures as can be seen in perovskite compounds. Conversely, NiMOF has a higher bandgap energy change, because it is included in the transition metal group with partially filled $d$-orbitals. It is commonly used as central atoms or cocatalysts to increase the energy in the conduction band hence increasing the bandgap energy value as well.

\section{Scanning Electron Microscopy and Structural Morphology of MOF Y-PTC}

Scanning electron microscopy (SEM) is a characterization method used to observe the surface morphology of a material with a very high magnification degree, while energydispersive $\mathrm{x}$-ray spectroscopy (EDS) is an analytical method used to determine the elements composing a material. Subsequently, the analysis using the SEM-EDS method is utilized in determining the structural morphology, homogeneity, and elemental composition of the synthesized Y-PTC. The results of SEM-EDS analysis on the Y-PTC compound are shown in Figure 7.

Figure 5 shows that Y-PTC MOF has an unclear structural morphology since its crystallinity degree is very low as shown by the previous XRD observations. Meanwhile, the EDS characterization showed the EDS spectrum Y-PTC (Figure 7) that exhibited the characteristic peaks for the composing elements such as carbon (72 1\%), oxygen $(20.7 \%)$, yttrium $(6.9 \%)$, and sodium $(0.3 \%)$. The presence of sodium in the Y-PTC was not completely removed in the washing process.

\section{Characterization of Surface Area with the Brunauer-Emmett-Teller (BET)}

The surface area characteristics of a porous material is measured using a Surface Area Analyzer (SAA) instrumentation. The basic principle of this measurement is based on the number of adsorbate molecules, adsorbed by the surface and pores of a material. Measuring the surface area of the Y-PTC MOF is very important in relation to its function as a photocatalyst. The larger the surface area, the active sites will be more presence at the catalyst for the photocatalytic reaction hence the photocatalytic activity increases.

The active sites and surface area have important roles in the reduction and oxidation reaction of water into hydrogen and oxygen. Furthermore, the surface area also greatly affects dye degradability. Photocatalysts with a large surface area tend to have high degradation ability since they were able to degrade through the adsorption mechanism. The photocatalyst materials should meet the thermodynamics requirement such as the potential for water splitting and photodegradation of dyes since it is possible that those two processes did not occur when the requirement did not meet. This caused by the absence of active sites on the photocatalyst surface as a place for the reaction. Those processes might also did not occur because the photogenerated electrons and holes experienced recombination. Based on the results of the BET analysis, MOF Y-PTC has a type IV adsorption curve with a surface area value of $47.7487 \mathrm{~m}^{2} / \mathrm{g}$ (Figure 8 ). 
Table 1. The bandgap energy value (Eg) of MOF based on the perylene ligand

\begin{tabular}{llllll}
\hline Sample & Metals & Ligand & $\mathbf{E g}(\mathbf{e V})$ & $\boldsymbol{\lambda}_{\max }(\mathbf{n m})$ & References \\
\hline PTCDA & - & PTCDA & 2.11 & 587 & Sigma Aldrich \\
Ni-MOF & Nickel & PTCDA & 2.41 & 514 & Zulys et al., 2020 \\
Dy-MOF & Dysprosium & PTCDA & 2.182 & 568 & Christina et al., 2020 \\
Sm-MOF & Samarium & PTCDA & 2.196 & 564 & \\
Y-PTC MOF & Yttrium & PTCDA & 2.23 & 563 & This work \\
\hline
\end{tabular}

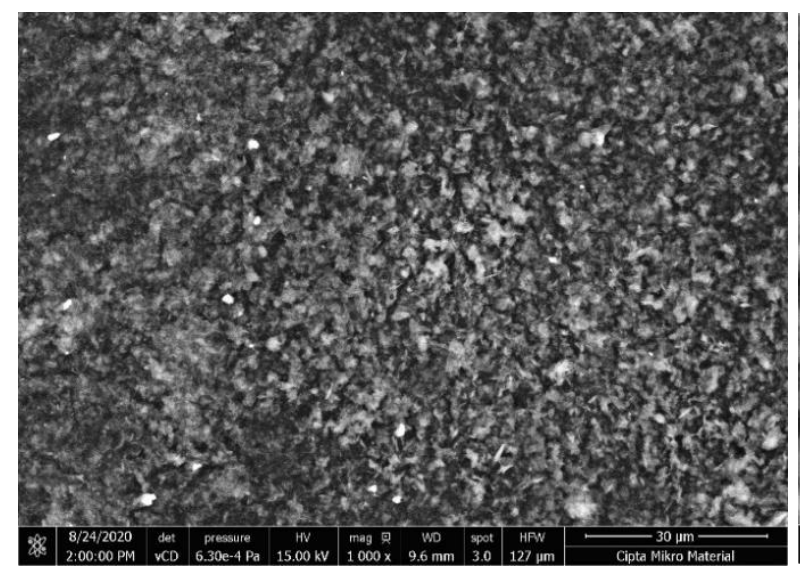

(a)

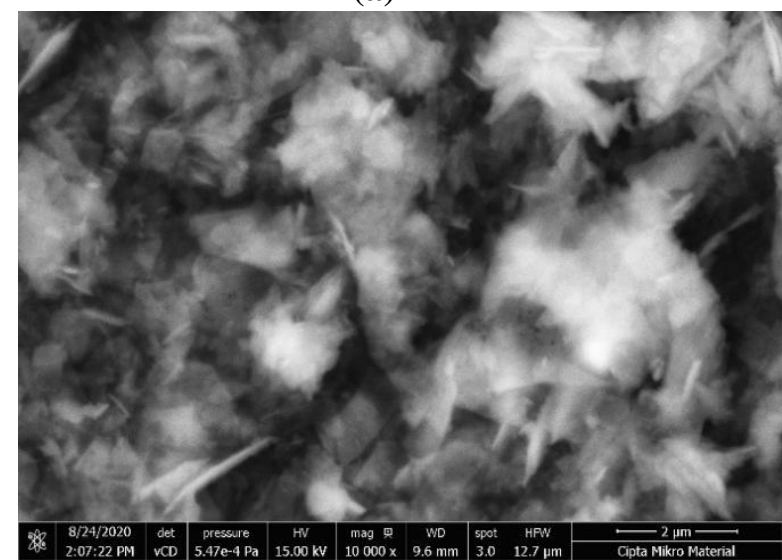

(c)

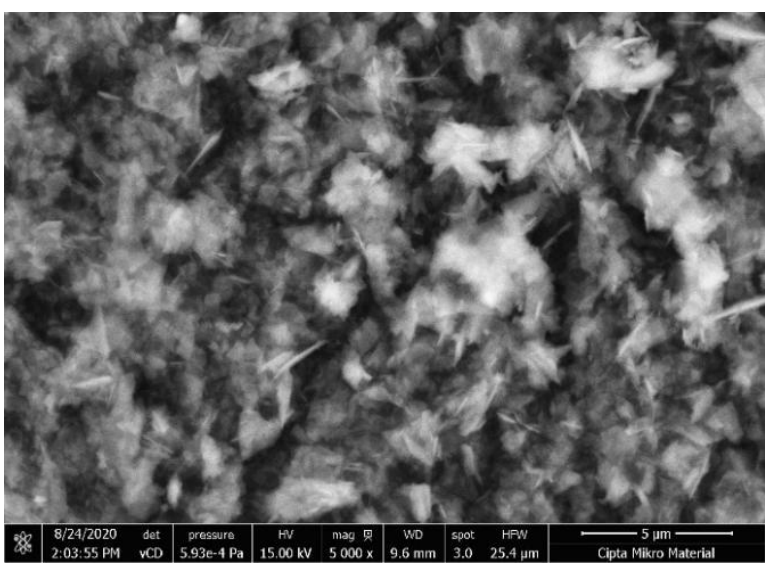

(b)

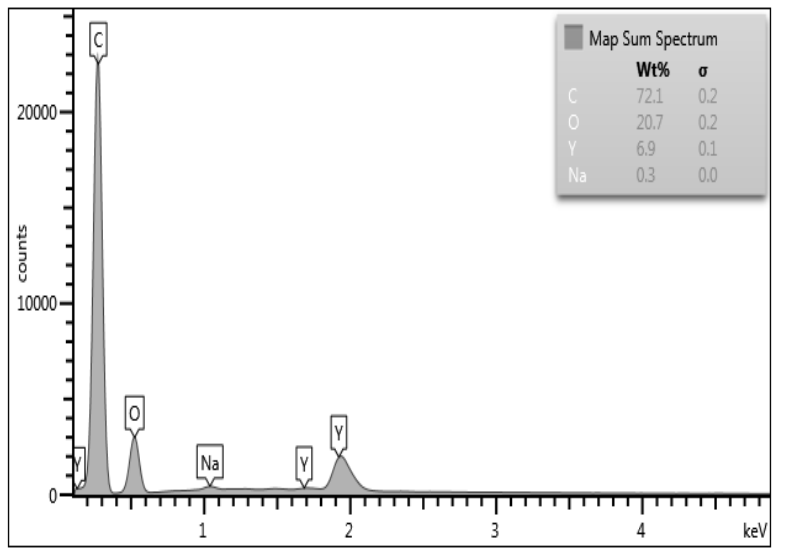

(d)

Figure 7. Y-PTC MOF morphology (a) Magnification of 1000x, (b) Magnification of 5000x, (c) Magnification of 10000x and (d) EDS spectrum of the Y-PTC MOF elements composition

Besides the surface area of MOF YPTC, BET analysis was also carried out to determine the pore size distribution of the material. Figure 8 shows the distribution of pore radii contained in the MOF Y-PTC sample. It was observed that the largest pore size distribution was in the radii with a range of $2-25 \mathrm{~nm}$. The figure also shows that the synthesized MOF Y-PTC is included in the mesoporous material, due to its pore diameter in the range of 2 to $50 \mathrm{~nm}$ (Ambroz et al., 2018). Although the surface area of MOF is still relatively small, this material is included in the mesoporous group. Mesoporous-sized materials have the advantage of being used as semiconductors since they provide a short distance hence reducing or preventing the recombination of photo-excited electrons and holes.

\section{Thermogravimetric Analysis}

Thermogravimetric analysis is used to determine the thermal stability of a material, such as the temperature at which it tends to be stable, begins to decompose, and the compounds produced. This analysis was 
carried out on $\mathrm{N}_{2}$ and $\mathrm{O}_{2}$ atmospheric conditions at an initial temperature of $20{ }^{\circ} \mathrm{C}$ to $500{ }^{\circ} \mathrm{C}$ with a heating rate of $20^{\circ} \mathrm{C} / \mathrm{min}$. The TGA analysis shows the relationship between the decrease in sample mass and the increase in temperature. Based on the thermogravimetric analysis on the Y-PTC MOF material, it shows relatively stable properties at $0{ }^{\circ} \mathrm{C}$ to $350{ }^{\circ} \mathrm{C}$, and has a sharp mass decrease in the temperature range above $400{ }^{\circ} \mathrm{C}$. The high temperature of MOF Y-PTC decomposition indicated that the synthesis product is a material that is strong and stable at high temperatures.

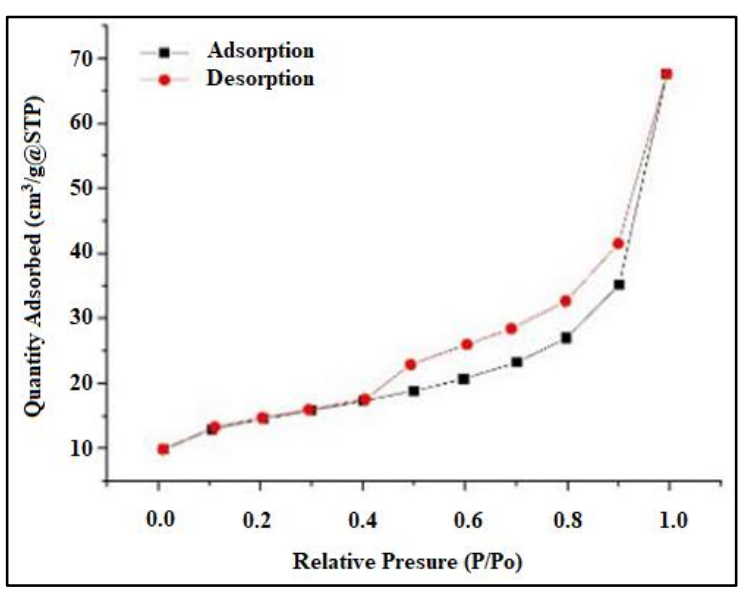

Figure 8. Adsorption and desorption isotherm curves of MOF Y-PTC

\section{Photocatalytic Activity in Dyes Photodegradation (Methylene Blue and Methyl Orange)}

The measurement of photocatalytic activity was carried out by dispersing the photocatalyst into $50 \mathrm{~mL}$ of dye solution (MB/MO), with a concentration of $10 \mathrm{mg} / \mathrm{L}$. The mixture was then stirred at $300 \mathrm{rpm}$ and allowed to stand in the dark condition for 60 mins. Further, the mixture was irradiated using a 250 watt mercury lamp as a visible light source for 240 mins. The dye concentration was measured using a UV-Vis spectrophotometer with a sampling period of 30 mins intervals. The photocatalytic activity of Y-PTC against methylene blue and methyl orange dyes was carried out under the conditions of $30 \mathrm{mg}$ Y-PTC MOF with an addition of $0.2 \mathrm{M} \mathrm{H}_{2} \mathrm{O}_{2}$ and $0.2 \mathrm{M} \mathrm{CH}_{3} \mathrm{OH}$. The measurements result on the photocatalytic activity of Y-PTC against $\mathrm{MB}$ and MO degradation are shown in Figure 9.

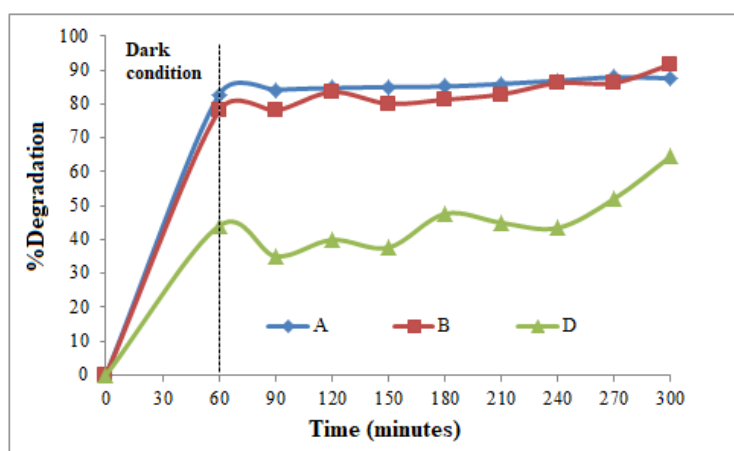

(a)

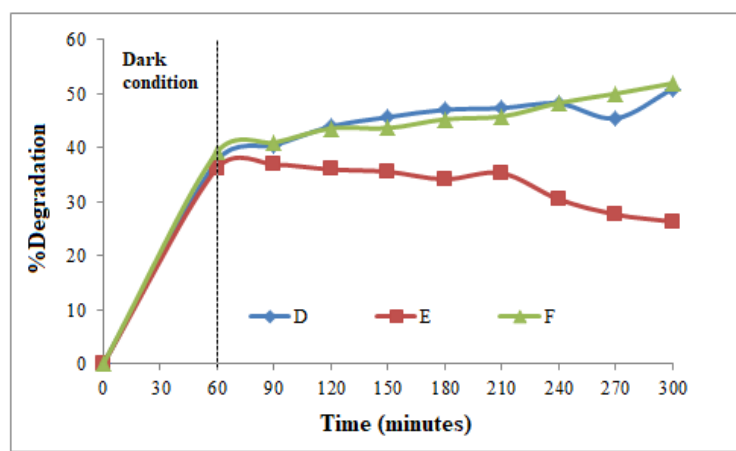

(b)

Figure 9. (a) The degradation efficiency of methylene blue $\left(\mathrm{A}=\mathrm{Y}-\mathrm{PTC} ; \mathrm{B}=\mathrm{Y}-\mathrm{PTC}+\mathrm{H}_{2} \mathrm{O}_{2} ; \mathrm{C}\right.$ $\left.=\mathrm{Y}-\mathrm{PTC}+\mathrm{CH}_{3} \mathrm{OH}\right)$ and $(\mathrm{b})$ methyl orange $(\mathrm{D}=\mathrm{Y}$ $\left.\mathrm{PTC} ; \mathrm{E}=\mathrm{Y}-\mathrm{PTC}+\mathrm{H}_{2} \mathrm{O}_{2} ; \mathrm{F}=\mathrm{Y}-\mathrm{PTC}+\mathrm{CH}_{3} \mathrm{OH}\right)$.

Dye degradation mechanism through a photocatalyst can occur through three approaches, (1) the dye directly carry the electron-pair \& electron-hole charges, (2) indirect degradation through oxidation/reduction and (3) direct degradation through photolysis with a larger or equal value of band gap energy which excited the electron (e) from valence band to conduction band and leave the electron-hole $(\mathrm{h}+)$ in valence band with an equal amount (Pingmuang et al., 2017). The highest oxidation potential from electronhole $\left(\mathrm{h}^{+}\right)$in photocatalyst valence band will oxidize the dye directly generate intermediate and cationic and anionic radical of dye which are reactive and further degraded. The reaction mechanism is showed in equation 6-8 and Figure 10 (Natarajan et al., 2017).

$$
\begin{aligned}
& \mathrm{MOF}+\mathrm{hv} \rightarrow \operatorname{MOF}\left(e_{C B}^{-}+h_{V B}^{+}\right) \\
& h_{V B}^{+}+\mathrm{Dye} \rightarrow \mathrm{Dye}^{*} \rightarrow \mathrm{Dye}^{+} \rightarrow \text { product } \\
& e_{C B}^{-}+\text {Dye } \rightarrow \mathrm{Dye}^{*} \rightarrow \mathrm{Dye}^{-} \rightarrow \text { product }
\end{aligned}
$$




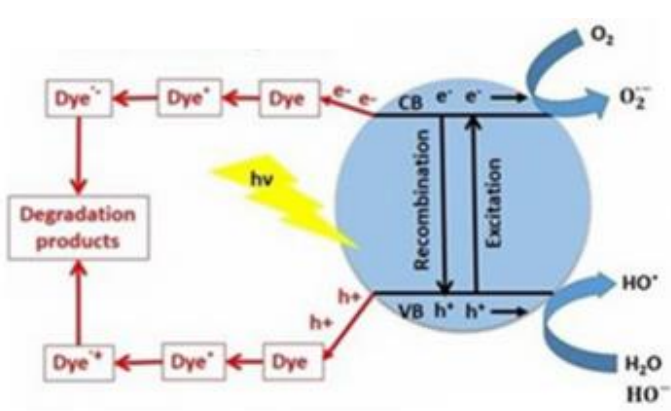

Gambar 10. Dye degradation through electron-pair and electron-hole injection (Isac et al., 2019)

When a photon is absorbed by the photocatalyst, the electron will be excited to the conduction band and leaving the electronhole in the valence band. The electron-pair and electron-hole are contributed to the reductionoxidation reaction (Al-mamun et al., 2019). However, in this type 2 mechanism, crucial thing occurred is electron recombination and hole which deactivated the photocatalyst. Therefore, to avoid the recombination, the common way is to add a substance or chemical which triggered the electron in photocatalyst conduction is continuously react with the oxygen which absorbed at the surface of the catalyst to generate superoxide radical $\left(\cdot \mathrm{O}_{2}\right)$ and the electron-hole will react with the water to form hydroxyl radical $(\bullet \mathrm{OH})$ then further degrade the dye (Isac et al., 2019). Meanwhile, the type three mechanism is a dye degradation using light without the presence of a photocatalyst and this type of mechanism will need a longer time. It was observed that $\mathrm{Y}$ PTC has photocatalytic activity against the degradation reaction of methylene blue and methyl orange with degradation efficiency of $87.55 \%$ for MB and 50.89 for MO.

The photocatalytic activity of MOF YPTC toward MB and MO is also observed by using the addition of hydrogen peroxide $\left(\mathrm{H}_{2} \mathrm{O}_{2}\right)$ and methanol $\left(\mathrm{CH}_{3} \mathrm{OH}\right)$. The role of the $\mathrm{H}_{2} \mathrm{O}_{2}$ and $\mathrm{CH}_{3} \mathrm{OH}$ is an electron scavenger and electron-hole scavenger, respectively. The addition of both sacrificial agents is expected to increase the Y-PTC photocatalytic activity and to understand its contribution toward the degradation of $\mathrm{MB}$ and $\mathrm{MO}$. The addition of $\mathrm{H}_{2} \mathrm{O}_{2}$ to the mixture caused the photocatalytic activity of Y-PTC to decrease MO degradation. This was observed from a significant decrease of $\mathrm{MO}$ degradation from $50.89 \%$ to $26.38 \%$. In contrast, the addition of $\mathrm{H}_{2} \mathrm{O}_{2}$ had a positive effect on the degradation of $\mathrm{MB}$ with a degradation efficiency of $87.55 \%$ to $91.17 \%$. $\quad \mathrm{CH}_{3} \mathrm{OH}$ addition contributed a small increase of degradation efficiency for $\mathrm{MB}$ and $\mathrm{MO}$ from $87.55 \%$ to $64.50 \%$ and $50.89 \%$ to $51.93 \%$, respectively.

The increase of the MB degradation percent with the addition of $\mathrm{H}_{2} \mathrm{O}_{2}$ is larger than the addition of $\mathrm{CH}_{3} \mathrm{OH}$ which showed that the free radical species $(\cdot \mathrm{OH})$ is a dominating species that contributed toward the photocatalytic degradation reaction. MB photocatalytic degradation mechanism can occur when the irradiated MOF Y-PTC will generate the photoexcitation of electron from the valence band to conduction band and leaving the electron-hole in the valence band. After that, the $\mathrm{H}_{2} \mathrm{O}_{2}$ added into the system will capture the photoexcited electron; hence avoid the recombination between the photoexcited electron and electron-hole. $\mathrm{H}_{2} \mathrm{O}_{2}$ also will react with the photoexcited electron generated the radical $(\bullet \mathrm{OH})$ and hydroxide $\left(\mathrm{OH}^{-}\right)$. The electron-hole in the valence band at the MOF will be stabilized by the bonding with the hydroxy species or other species such as water which generated hydroxyl radical $(\bullet \mathrm{OH})$. The decomposition of $\mathrm{H}_{2} \mathrm{O}_{2}$ by irradiation is then generated $(\bullet \mathrm{OH})$, therefore increasing the amount of hydroxyl radical $(\bullet \mathrm{OH})$ to degrade the MB (equation 7-13).

$$
\begin{aligned}
& \mathrm{Y}-\mathrm{PTC}+\mathrm{hv} \rightarrow \mathrm{MOF} \text { Y-PTC }\left(e_{C B}^{-}+h_{V B}^{+}\right) \\
& e_{C B}^{-}+\mathrm{H}_{2} \mathrm{O}_{2} \rightarrow \cdot \mathrm{OH}+\mathrm{OH}^{-} \\
& e_{C B}^{-}+\mathrm{O}_{2} \rightarrow \cdot \mathrm{O}_{2} \\
& h_{V B}^{+}+\mathrm{OH}^{-} \rightarrow \cdot \mathrm{OH} \\
& h_{V B}^{+}+\mathrm{H}_{2} \mathrm{O} \rightarrow \cdot \mathrm{OH} \\
& h_{V B}^{+}+\mathrm{CH}_{3} \mathrm{OH} \rightarrow \cdot \mathrm{CH}_{2} \mathrm{OH} \\
& h_{V B}^{+}+\cdot \mathrm{CH}_{2} \mathrm{OH} \rightarrow \mathrm{CH}_{2} \mathrm{O}
\end{aligned}
$$

On the other hand, when a sacrificial agent such as methanol is added into the system, the electron-hole will be captured, oxidized the methanol into hydroxyalkyl radical $\left(\cdot \mathrm{CH}_{2} \mathrm{OH}\right)$, and further oxidized into formaldehyde $\left(\mathrm{CH}_{2} \mathrm{O}\right)$. No hydroxyl radical $(\cdot \mathrm{OH})$ formation was observed for the MB photodegradation process. However, the photoexcited electrons will react with the oxygen adsorbed on the surface of Y-PTC MOF forming the superoxide radical $\left(\cdot \mathrm{O}_{2}\right)$ 
which will react with the dye to form a degradation product. Fakhrul et al., 2018 reported that superoxide radical showed less energy than the hydroxyl radical. Thus, the degradation efficiency percent of the dye with the addition of $\mathrm{H}_{2} \mathrm{O}_{2}$ is higher than using methanol $\left(\mathrm{CH}_{3} \mathrm{OH}\right)$.

Unlike the MB, MO degradation by MOF Y-PTC showed a better result when a sacrificial agent such as methanol is added with the increasing degradation from $50.89 \%$ to $51.93 \%$, while $\mathrm{H}_{2} \mathrm{O}_{2}$ addition decreased the MO degradation from $50.89 \%$ to $26.38 \%$.

\section{CONCLUSION}

Metal-organic framework based on yttrium metal ion and perylene ligands was successfully synthesized through the solvothermal method at $170{ }^{0} \mathrm{C}$ for 24 hours. The results of FTIR characterization showed that MOF Y-PTC has a different structure and composition from its precursor, $\mathrm{Na}_{4} \mathrm{PTC}$. Also, it has a bandgap energy of $2.20 \mathrm{eV}$ and a surface area of $47.7487 \mathrm{~m}^{2} / \mathrm{g}$. Based on the SEM-EDS analysis, Y-PTC has elemental compositions of yttrium, carbon, and oxygen by $6.9 \%, 72.1 \%$, and $20.7 \%$, respectively. This material Y-PTC MOF has a photocatalytic activity against the degradation of methylene blue and methyl orange with degradation efficiency of $87.55 \%$ and $50.89 \%$ respectivelly. The $\mathrm{H}_{2} \mathrm{O}_{2}$ addition to the mixture caused the enhanced photocatalytic activity of Y-PTC to degrade MB. In contrast the addition of $\mathrm{CH}_{3} \mathrm{OH}$ has a positive effect to degrade MO. Therefore, MB degradation by Y-PTC is affected by hydroxyl radical $(\cdot \mathrm{OH})$ and hole $\left(\mathrm{h}^{+}\right)$while $\mathrm{MO}$ is affected by superoxide radical $\left(\cdot \mathrm{O}_{2}\right)$ and photoexcited electron $\left(\mathrm{e}^{-}\right)$.

\section{ACKNOWLEDGMENT}

The authors are grateful to the Ministry of Research, Technology and Higher Education for funding the research activity carried out and Integrated Laboratory Centre (PLT) UIN syarif Hidayatullah Jakarta for facilitate the enforcement of this research.

\section{REFERENCES}

Al-mamun, M. R., Kader, S., Islam, M. S., \& Khan, M. Z. H. (2019). Journal of Environmental Chemical Engineering Photocatalytic activity improvement and application of $\mathrm{UV}-\mathrm{TiO}_{2}$ photocatalysis in textile wastewater treatment: A review, 7(June). https://doi.org/10.1016/j.jece.2019.103248

Ambroz F, Macdonald TJ, Martis V, Parkin IP. 2018. Evaluation of the BET theory for the characterization of meso and microporous MOFs. Small Methods. 2(11). doi: 10.1002/smtd.201800173.

Batubara NH, Zulys A. 2019. Synthesis, Structural, Spectroscopic, and Morphology of MetalOrganic Frameworks Based on la (III) and Ligand 2,6-Napthalenedicarboxylic acid (La-MOFs) for Hydrogen Production. IOP Conf. Ser. Mater. Sci. Eng. 546(4). doi: 10.1088/1757-899X/546/4/042005.

Christina, LC., Gunlazuardi, J., Zulys, A. (2020). Synthesis and characterization of lanthanide metal-organic framework Synthesis and characterization of lanthanide metal-organic. https://doi.org/10.1088/1757899X/902/1/012046

Fakhrul, M., Samsudin, R., Tau, L., \& Sufian, S. (2018). ScienceDirect Exploring the role of electron-hole scavengers on optimizing the photocatalytic performance of BiVO 4. Materials Today: Proceedings, 5(10), 21703-21709. https://doi.org/10.1016/j.matpr.2018.07.022

Isac, L., Cazan, C., Enesca, A., \& Andronic, L. (2019). Copper Sulfide Based Heterojunctions as Photocatalysts for Dyes Photodegradation, 7(October), 1-9. https://doi.org/10.3389/fchem.2019.00694

Kudo, A. \& Miseki, Y. Heterogeneous photocatalyst materials for water splitting w. 253-278 (2009). doi:10.1039/b800489g.

Natarajan, S., Bajaj, H. C., \& Tayade, R. J. (2017). Recent advances based on the synergetic effect of adsorption for removal of dyes from waste water using photocatalytic process. Journal of Environmental Sciences, $1-22$. https://doi.org/10.1016/j.jes.2017.03.011

Pingmuang, K., Chen, J., Kangwansupamonkon, W., Wallace, G. G., Phanichphant, S., \& Nattestad, A. (2017). Composite Photocatalysts Containing $\mathrm{BiVO}_{4}$ for Degradation of Cationic Dyes. Scientific Reports, (May), 1-11. https://doi.org/10.1038/s41598-017-09514-5 
Ramasundaram S, M.G. Seid, J.W. Choe, E.-J. Kim, Y.C. Chung, K. Cho, C. Lee, S.W. Hong, Highly reusable $\mathrm{TiO} 2$ nanoparticle photocatalyst by direct immobilization on steel mesh via PVDF coating, electrospraying, and thermal fixation, Chem. Eng. J. 306 (2016) 344-351.

Sikdar, N. et al. Coordination-driven fuorescent Jaggregates in a perylenetetracarboxylatebased MOF: permanent porosity and proton conductivity. Te Journal of Physical Chemistry C 120, 13622-13629 (2016).

Wang, C., Li, J., Lv, X., Zhang, Y., \& Guo, G. (2014). Environmental Science metal organic frameworks. Energy \& Environmental Science, 7, 2831-2867. https://doi.org/10.1039/C4EE01299B

Yuan, S., Feng, L., Wang, K., Pang, J., Bosch, M.,
Lollar, C., ... Zou, L. (2018). Stable Metal Organic Frameworks: Design, Synthesis , and Applications, 1704303, 1-35. https://doi.org/10.1002/adma.201704303

Zulys, A., Asrianti, D., \& Gunlazuardi, J. (2020). Synthesis and characterization of metal organic frameworks based on nickel and perylene dyes as water splitting photocatalyst Synthesis and Characterization of Metal Organic Frameworks Based on Nickel and Perylene Dyes as Water Splitting Photocatalyst, 020035, 5-9.

Zulys, A,, Adawiah, A., Gunlazuardi J., Yudhi M. D. L. (2021). Light-harvesting MetalOrganic Frame-works (MOFs) La-PTC for photocatalytic dyes degradation. Bulletin of Chemical Reaction Engineering \& Catalysis. 16(1): 170-178. doi:10.9767/bcrec.16.1.10309.170-178. 